


\title{
PERSPECTIVAS DE LA POSMODERNIDAD INSTITUCIONAL
}

\author{
INSTITUTIONAL PERSPECTIVES OF POSMODERNITY
}

\author{
José G. Vargas-Hernández*
}

\section{Resumen}

Este trabajo tiene como objetivo analizar las perspectivas teórico-metodológicas del posmodernismo como tendencia de la política comparativa. A pesar de que los posmodernistas frecuentemente rechazan algunos de los puntos del acercamiento conductual, la psicología política tiende a abarcarlos. En este análisis se sugiere que se debe tener cuidado cuando se atribuyen elementos al posmodernismo ya que está lejos de ser una disciplina monolítica, pues contiene diferentes áreas de interés, tales como el posestructuralismo. La posmodernidad cuestiona la legitimidad del desarrollo alcanzado por la modernidad y la universalidad de sus valores y procesos, el reduccionismo economicista, su enfoque etnocéntrico y la unidimensionalidad de su interpretación.

\section{Palabras clave}

Constuctivismo, instituciones, posmodernismo.

\section{Abstract}

This paper aims to analyze the theoretical methodological perspectives of postmodernism as a tendency of comparative politics. Although postmodernists frequently reject some of the points of behavioral approaching, the psychological politics tend to embrace them.

\footnotetext{
* M.B.A. y Ph.D., profesor investigador miembro del Sistema Nacional de Investigadores, Departamento de Mercadotecnia y Negocios Internacionales, Centro Universitario de Ciencias Económico Administrativas, Universidad de Guadalajara.
} 
In this analysis it is suggested that you must be careful when elements are attributed to postmodernism which is far beyond being a monolithic discipline, because it contains different areas of interest, such as poststructuralism. Postmodernity questions the legitimacy of the development achieved by modernity and the universality of its values and processes, the economics reductionism, its ethnocentric focus and its unidimensional interpretation.

\section{Keywords}

Constructivism, institutions, postmodernism.

\section{Conceptualización de la posmodernidad}

El mundo contemporáneo despliega sistemas internacionales múltiples en operación: un sistema posmoderno, kantiano, inhibido por los miembros de la Unión Europea; un sistema moderno lockeano, experimentado por los que están cerca de la Unión Europea y un sistema hobbesiano, con condiciones que perversas. Las instituciones creadas por la modernidad son las garantes de cuidar mediante procesos de estrictas disciplinas aplicadas a los disidentes para conformar y obligar a los comportamientos humanos a adaptarse y sujetarse a la racional instrumental de los mandatos del poder fascinante y formas de gobierno que más convienen a los intereses del desarrollo capitalista de los pueblos occidentales.

A partir del análisis de la modernidad y la posmodernidad como formas de sustentabilidad social, bajo los supuestos de que los modernistas asumen que la función primaria de la organización económica es la producción, los posmodernistas asumen que la producción de cosas físicas es sobrepasada por la producción de bienes de información y servicios. Los posmodernistas asumen que la producción de cosas físicas es sobrepasada por la producción de bienes de información y servicios. Se debe tener cuidado cuando se atribuyen elementos al posmodernismo ya que está lejos de ser una disciplina monolítica, ya que contiene diferentes áreas de interés, tales como el postestructuralismo. La postmodernidad cuestiona la legitimidad del desarrollo alcanzado por la modernidad y la universalidad de sus valores y procesos, el reduccionismo economicista, su enfoque etnocéntrico y la unidimensionalidad de su interpretación. Se cuestiona al paradigma racionalista cuidadosamente elaborado por sus orígenes en el cogito ergo sum cartesiano con el cenit en el idealismo alemán, que se ha perfeccionado en su estructura conceptual en los siglos de la modernidad pero que ha encontrado su agotamiento en los límites de su propia perfección y ha sucumbido a la tentación soberbia.

La ciencia para los posmodernistas es una actividad social y política contaminada por la búsqueda del poder y las ideologías espurias. Mientras que los positivistas consideran esencial una fundamentación objetiva, universal y libre de ideología, los posmodernistas consideran una simulación, un mito ideológico que obscurece la verdadera naturaleza de la ciencia, un sirviente del excluyente status quo social. La ciencia es una ideología basada y prejuiciado por la actividad política. La ciencia posmoderna proporciona las bases metodológicas y de contenido para un pro- 
yecto económico-político. En estas etapas sucesivas, por ejemplo, Foucault intenta transplantar las ciencias naturales y exactas a otros campos al mismo tiempo que es escéptico del método racional y critica al humanismo. Este proyecto concibe "la trasgresión de las fronteras, el derrumbamiento de las barreras, la democratización radical de todos los aspectos de la vida social, económica y política" (Sokal y Bricmont, 1999).

\section{Emergencia de la posmodernidad}

Se reprocha que el posmodernismo pusiera el último clavo en el ataúd de la Ilustración y la izquierda enterró los ideales de justicia y progreso. La esencia de la Ilustración es el ejercicio racional de la crítica y se perfecciona enfrentando sus propios defectos de raciocinio. Pero las tesis de posmodernidad y sentencian la decadencia de la modernidad ilustrada porque es excluyente de la pluralidad, la multiplicidad, la hibrides y la ambigüedad. La "tendencia posmoderna de pensamiento" apareció recientemente como expresión o aprehensión de una realidad social específica que hace referencia al pensamiento emergente de la modernidad tardía o de la era postindustrial manifiesta en las condiciones de vida específicas de los grandes centros urbanos de los países desarrollados, o bien como una cultura conformada por un conjunto de modos de vida en las regiones hiperindustrialzadas. La conexión de las abstracciones generales, como sociedad, Estado e imperio con otros significantes, como sociedad industrial en contra de sociedad posindustrial, Estado soberano contra Estado del mercado, imperio formal contra imperio informal, etc., proveen un mejor entendimiento de las relaciones entre la investigación empírica y las abstracciones conceptuales (Giddens, 1991) opone a la idea de posmodernidad la de modernidad radicalizada y hace la crítica del movimiento posestructuralista en el que se deriva y debe superarse porque considera que hay insuficiencias en los análisis de la modernidad de los siglos XIX y XX.

Los derechos humanos emergen después de la Guerra Fría como un discurso normativo. En la posmodernidad, los derechos humanos se plantean como cuestión relacionada con un proyecto de ética política para dar sustento a la libertad y los derechos de los seres humanos en convivencia humana mediante las expresiones libres, tolerantes y toleradas de las subjetividades múltiples, las pluralidades y los intereses de una nueva sociedad. A partir de los años setenta se opera el período genealógico con la influencia del perspectivismo y Nietzsche en una actitud militante en contra de la represión, una desconfianza hacia el discurso académico que se expresa en el posestructuralismo, identificado con el posmodernismo irracionalista y nihilista que rechaza el método científico, al pensamiento racional y abuso de la ciencia como metáfora. Si la modernidad capitalista fue la creadora del Estado-nación y sus principales creaciones, como una sociedad y mercado nacionales, fronteras, ejércitos, etc., cuando el capitalismo entra en crisis, aunque muy discutible, entonces necesariamente entran en crisis todas estas instituciones, ya en transición hacia la posmodernidad.

Una nueva época quedó delimitada a partir de 1989 con la implosión del sistema socialista soviético y el auge de una nueva concepción más centrada en la mera subjetividad de la vida y del mundo denominada posmodernidad. La modernización era vista como un proceso de diferenciación estructural e integración funcional donde tenían lugar las categorías de clasificación del mundo, pero para Giddens $(1984,1990)$ la teoría de la modernización es vista como un proceso de distanciamiento espacio temporal, en el cual el tiempo y el espacio se desarraigan de un 
espacio y un tiempo específicos, proceso que es más bien posmoderno. Los cambios en la geografía social rural entran en procesos de extinción en el siglo pasado que se manifiesta en el éxodo de una mayor parte de campesinos que abandonan el campo y su cosmovisión de la vida rural, quedando menos de un $3 \%$ en las sociedades más avanzadas, para integrarse a las redes de la vida urbana posmoderna y posindustrial. La globalización es consecuencia ineludible de la modernidad capitalista que deriva en la posmodernidad, y por lo tanto, en un preconizado relativismo que socava la crítica social, para el cual la objetividad es una mera convención social. Un inmovilismo discursivo está invadiendo a la sociedad posmoderna. La globalización puede ser vista como una continuidad del voluntarismo para establecer el ideal de una sociedad justa y afluente mediante la creación del Estado de bienestar y de las tesis desarrollistas, pero con adaptaciones a la cultura de la posmodernidad. Es a finales del siglo XX cuando se manifiestan libremente las tendencias de la posmodernidad en las subjetividades múltiples y las multiplicidades subjetivas como expresiones amalgamadas de antecedentes históricos, biológicos, genéticos, psíquicos, culturales, lingüísticos, etc., estas expresiones se salen de los marcos referenciales de la racionalidad instrumental ilustrada tan defendida por las instituciones de la modernidad. La lógica cultural del capitalismo tardío es el posmodernismo donde el espacio se interpreta como un símbolo y una realidad privilegiada.

\section{Caracterización de la posmodernidad}

Si la característica fundamental de la modernidad es la densidad de los cambios, la característica principal de la posmodernidad es la aceleración de estos cambios caracterizados por su complejidad e incertidumbre, por una fenomenología caótica-teoría del caos-que modifica constantemente los procesos económicos, políticos, sociales, culturales, etc. La complejidad cultural surge del choque entre la modernidad y la tradición de las varias formas de la interactividad de las redes. Estas redes de producción multinacionales representan nuevas formas de organización global posmodernas, en donde el concepto de economías basadas geográficamente ya no es relevante. En la posmodernidad prevalece la idea de que la realidad es compleja y multicausal, en cambio continuo, que acepta diferentes racionalidades con relación a las variables a optimizar y que nada está garantizado o predeterminado.

La posmodernidad cuestiona las variables sociales, culturales, del medio ambiente, políticas y éticas de la ecuación del desarrollo y su proyecto modernizador. La inclinación del posdesarrollo sobre "el lugar", la ecología política y la geografía posmoderna al estudiar la globalización permite reconocer los modos de conocimiento y modelos de naturaleza basados en lo local (Escobar, 2000: 172). Las orientaciones posmodernas que son condicionantes de los principales agentes de los procesos de globalización, las corporaciones transnacionales y multinacionales, al decir de Santos son la unicidad de la tecnología, del tiempo y de la plusvalía como motor del desarrollo (1993). El tiempo tiene poco significado y el espacio se comprime como resultado del avance tecnológico. En el posmodernismo no existen fronteras ni alternativas para el futuro, sino una reiteración de lo mismo a través del empleo de las tecnologías. En el período avanzado del posmodernismo se forman elaboraciones que desarrollan las tesis de las "técnicas de sí". El concepto de "espacio" evolucionó de una concepción territorial física a una concepción más dinámica y multilineal. Arellanes Jiménez caracteriza este nuevo concepto de espacio como un "concepto dinámico, 
abierto, cambiante, flexible y multilineal e histórico que se va aplicando a diversas circunstancias, coyunturas, cambios, actores, sujetos y relaciones". La desterritorialización del Estado-nación está dando lugar a nuevas formas espaciales geopolíticas y geoeconómicas. El surgimiento del Estado posnacional evoluciona el concepto de nación como el invento moderno que legitima el dominio de un pueblo politizado sobre un territorio determinado. Esta tendencia hacia el sí mismo multilocal es ya una característica de esta modernidad capitalista avanzada, del mismo modo que la tendencia hacia el espacio poliétnico o "desnacional” (Sloterdijk, 1999).

Las tendencias derechistas del posmodernismo se expresan con planteamientos tecnocientíficos conservadores de filósofos del stablishment que limitan las alternativas de acción política para superar la etapa de desarrollo de la humanidad, como en el fin de la historia de Fukuyama. De acuerdo con estos autores, las fuentes de un posmodernismo que se mueve hacia la izquierda política son: el descontento con la izquierda ortodoxa, su desorientación y la ciencia como un blanco fácil. La izquierda ha asimilado y repetido hasta la saciedad la retórica de la doctrina del libre mercado y a denunciar el desmantelamiento de las funciones del libre mercado. Sin embargo, entre sus efectos negativos se mencionan la pérdida de tiempo en las ciencias humanas, una confusión cultural oscurantista y el debilitamiento de la izquierda política. El posmodernismo radical que rechaza toda manifestación de la racionalidad es considerado como un relativismo cognitivo y es cuestionado por considerarlo un cientifismo dogmático frente al prestigio de la ciencia basada en el modelo racionalista.

Los conceptos de organización posburocrática, posmoderna, la organización posemprendedora y la firma flexible se refieren a nuevos principios organizacionales y expresan los nuevos paradigmas en las formas organizacionales. Otros aspectos específicos de estos paradigmas incluyen el federalismo, la corporación virtual, la corporación reingenierizada, la compañía creadora de conocimiento, la organización "ambidexterus", de alto desempeño o sistemas de trabajo de alto compromiso, la organización híbrida y la "solución transnacional”, etc.

La solución transnacional es una visión de una red integrada en la cual el centro corporativo guía los procesos de coordinación y cooperación entre las unidades subsidiarias en un clima de toma de decisiones compartidas, mezcla la jerarquía con la red y retiene la creación del valor en una corporación (Bartlett y Ghoshal, 1998). Cambios en las metas de las organizaciones para responder a la incertidumbre, el enfoque estratégico en el diseño de procesos y estructuras, un énfasis en lo social e interpersonal y una reemergencia de la legitimidad.

\section{Implicaciones de la posmodernidad en Latinoamérica}

Hay escasas evidencias de que la región latinoamericana consiste de "sociedades posmodernas" o que se está moviendo a una era posmoderna. Muchos de los habitantes de las regiones menos desarrolladas en Latinoamérica viven bajo condiciones que pueden ser descritas como modernidad desigual más que posmodernidad. La complejidad de la realidad social de Latinoamérica contemporánea es quizás pensada como una complejidad híbrida de ideologías, prácticas y condiciones de la premodernidad, modernidad y posmodernidad. De hecho, los procesos contemporáneos de la globalización y la expansión del capitalismo tardío o posmoderno han agravado los más crónicos problemas del desarrollo económico y social como en el caso de la región latinoamericana. Los procesos de globalización aunados al 
crecimiento incontrolable de megalópolis en algunos países menos desarrollados crean nuevas formas de organización y desorganización que someten a la población a una brutal competencia de tal forma que establecen similitudes y diferencias en las que se mezclan rasgos de la modernidad y la posmodernidad marcados con la realidad de las sociedades desarrolladas.

Lechner señala que en la posmodernidad inciden como tendencias el desmoronamiento de la fe en el progreso y una creciente sensibilidad acerca de los riesgos fabricados por la modernización; el auge del mercado y el consiguiente debilitamiento de la política como instancia reguladora y el cuestionamiento de la noción misma de sociedad como sujeto colectivo capaz de moldear su ordenamiento (2000). El mayor daño que el posmodernismo causa a los países en desarrollo es una guerra de culturas para convertirse en consumidores acríticos de culturas foráneas si se considera como el reflejo múltiple de la cultura de la posmodernidad donde el trabajo de la Ilustración no ha concluido y en donde se identifican el irracionalismo posmoderno con las mentalidades irracionales que no acaba de realizar la civilización.

La posmodernidad alienta la revisión de las culturas y a replantear sus relaciones con la visión de los valores occidentales. La posmodernidad de la cultura política se caracteriza por una fragmentación de valores compartidos por las colectividades y el distanciamiento de los ciudadanos a las instituciones, marcado por una creciente desconfianza que provoca crisis de las democracias institucionalizadas. La "macro dictadura total" del neoliberalismo, como sostiene el obispo de Sao Felix do Araguaia, Brasil, que se impone como pensamiento único con sus "teólogos del diablo" y su posmodernidad narcisista (Fazio, 2000) En el sueño de la posmoderni- dad los individuos pueden imaginar transitar por la vida sin conceptos.

\section{Críticas a la posmodernidad}

Las críticas al desarrollo de la posmodernidad se interesan por los paradigmas alternativos que enfatizan el establecimiento de metas desde una tradición y cultura, participación en la toma de decisiones y en la acción de contenidos de desarrollo (Goulet, 1999). En ocasiones, desde la perspectiva de posmodernidad, los actores que se desvían de las reglas del juego son apreciados positivamente por las posibles contribuciones que realizan. Las críticas de los pensadores posmodernistas en relación con las exclusiones y desigualdades en el actual orden social es justa, así como también se debe estar conscientes de las posibles consecuencias del relativismo moral y epistémico basado en las fragmentaciones. La extrema posmodernidad de la literatura ideacional confronta los problemas negándolos y privilegiando la interpretación como la meta de la investigación, rechazando así la noción de un objetivo contextual que puede ser evaluado y medido. La universalidad de la moralidad provee los fundamentos y media la fragmentación causada por la posmodernidad.

\section{Referencias}

Bartlett, G. A. y Ghoshal, S. (1998). Managing Across Borders: The Transnational Solution ( $2^{\text {nd }}$ edition). Boston: Harvard Business School Press.

Escobar, A. (2000). El lugar de la naturaleza o la naturaleza del lugar globalización del posdesarrollo. En: Viola, A. (Comp.). Antropología del desarrollo. Teorías y estudios etnográficos en América Latina. Barcelona: Ediciones Paidós. 
Fazio, C. (2000). La solidaridad en los tiempos del neoliberalismo. La Jornada, Masiosare.

Giddens, A. (1990). The Consequences of Modernity. Cambridge: Polity.

Giddens, A. (1991). Modernity and Selfidentity. Stanford: Stanford University Press.

Giddens, A. (1990). The Consequences of Modernity. Stanford: Stanford University Press.

Giddens, A. (1984). The Constitution of Society. Los Angeles: University of California Press.
Goulet, D. (2000). Changing Development Debates under Globalization. Working paper, No. 276. The Hellen Kellog Institute for International Studies.

Lechner, N. (2000). Desafíos en el desarrollo humano: individualización y capital social. Instituciones y Desarrollo, núm. 7.

Sloterdijk, P. (1999). Patria y globalización. Nexos, 262.

Sokal, A. y Bricmont, J. (1999). La crítica al relativismo posmodernista. Este Pais, núm. 104. 